\title{
PESQUISA DA CONDUTA MANIFESTA DE 27 ENFERMEIRAS SOBRE A Utilização do técnico de enfermagem no CAMPo De SACDE PUBLICA *
}

\author{
Maria de Lourdes Rodrigues * *
}

\section{APRESENTAÇÃO DO PROBLEMA}

Sendo um dos aspectos da "Responsabilidade do Enfermeiro na Prestação de Serviços à Comunidade”, a previsão e a participação na provisão, de pessoal adequadamente qualificado para executar a programação de enfermagem, explica-se que os enfermeiros de saúde pública procurem bem se informar sobre os recursos disponíveis que facilitariam o desempenho desta responsabilidade. Colocam-se, então, pertinentemente, indagações tais como:

- Quais seriam as necessidades de pessoal de enfermagem em saúde pública?

- Que pessoal existiria no mercado de trabalho para suprir essas necessidades?

- Qual seria sua formação?

- Quais seriam suas atribuições em saúde pública? campo?

- Quais seriam as perspectivas para a sua utilização neste

Inúmeras outras questões se poderiam fazer, contribuindo para a conformação cada vez mais precisa dos problemas do dimensionamento e da provisão do pessoal de enfermagem em saúde pública, problemas cujo tratamento se beneficia óbvia e fortemente de pesquisas de campo.

O presente inquérito é uma pesquisa de campo, embora de proporções modestíssimas e com um objetivo equivalentemente modesto; seu ponto de partida foi a nossa constatação empírica de que muito pouco sabemos sobre o Técnico de Enfermagem no campo da saúde pública, por se tratar de uma categoria nova para nós.

\footnotetext{
(*) Anexo do Trabalho "Responsabilidade da Enfermeira na prestação de serviço à Comunidade."

$\left({ }^{* *}\right)$ Enfermeira da "Fundação Serviço Especial de Saúde Pública".
} 


\section{PLANO DA PESQUISA}

\section{1 - Finalidade da Pesquisa}

Nosso intuito foi o de levantar dados que pudessem contribuir para maiores esclarecimentos quanto a:

a) propriedade da utilização do serviço de enfermagem no setor da saúde pública;

b) tendências e perspectivas dessa utilização;

c) fatores que influiriam nessa utilização.

2 - Território Geográfico e Periodo em que se Verificou a Pesquisa

A pesquisa foi realizada no Distrito de São Paulo, em maio de 1972, entre 27 enfermeiras que exercem funções profissionais ou estão presentes nas seguintes instituições: Secretaria da Educação, Secretaria da Saúde, Faculdade de Saúde Pública da Universidade de São Paulo, Escolas de Enfermagem e Hospitais de Ensino.

\section{3 - Metodologia da Pesquisa}

\section{1 - Tipo da Pesquisa e do Instrumento}

Pela natureza dos dados procurados e devido ao condicionamento do tempo, determinamos fazer uma pesquisa básica, tipo "survey descritivo", com levantamento total, muito embora de caráter sumamente elementar, sem que nos fosse possível pretender uma formulação de hipóteses de maior significação ou alcance em profundidade e mesmo em extensão. Ficaremos, talvez, somente no limiar do problema que estamos colocando, iniciando sua discussão. A coleta de dados foi feita por meio de formulário.

\section{2 - Objetivos da Pesquisa}

Identificar fatores individuais que presumivelmente exerceriam influência sobre a conduta manifesta de 27 enfermeiras, em exercício de funções consideradas representativas relativamente ao tecnico de enfermagem, nas áreas de regulamentação do seu ensino, da estruturação da sua carreira, da sua formação e do seu exercício profissional, no sentido de opinarem favorável ou não favoravelmente à utilização do Técnico de Enfermagem no campo da saúde pública. 
Medir a influência dos fatores identificados sobre a conduta manifesta das 27 enfermeiras, no sentido de opinarem favorável ou não favoravelmente à utilização do Técnico de Enfermagem no campo da saúde pública.

\section{3 - Hipóteses}

a) O grau de conhecimentos específicos relativos ao Técnico dc Enfermagem, de enfermeiras em exercício de funções consideradas representativas em relação ao profissional supracitado, pode estar sujeito à existência ou inexistência de experiência prévia ou atual das referidas enfermeiras com o mesmo Técnico.

b) a conduta manifesta dessas enfermeiras, no sentido de opinarem favorável ou não favoravelmente sobre a utilização do Técnico de Enfermagem no campo da saúde pública pode variar em função da existência ou inexistência de experiência prévia ou atual das mesmas enfermeiras com este Técnico.

c) a conduta manifesta dessas enfermeiras, no sentido de opinarem favorável ou não favoravelmente sobre a utilização do Técnico de Enfermagem no campo da saúde pública pode variar em função do grau de conhecimentos específicos das enfermeiras relativamente a esse profissional.

\section{4 - Delimitação do Universo}

O universo escolhido para a pesquisa foi o Distrito de São Paulo, com as seguintes estratificações:

A - Secretaria de Estado dos Negóciós da Educação do Estade de São Paulo - na sua Comissão Permanente da Área Terciária (Saúde).

B - Secretaria de Estado da Saúde do Estado de São Paulo, nos seus setores de: Conselho de Saúde, Coordenadoria de Saúde da Comunidade, Coordenadoria de Assistência Hospitalar.

C - Associação Brasileira de Enfermagem, nos seus setores de Presidência, em nível nacional e estadual (São Paulo) e de Comissão de Documentação e Estudos.

D - Faculdade de Saúde Pública da USP, no seu Departamento de Prática de Saúde Pública - Curso de Enfermagem de Sáúde Pública e Chefia da Seção Técnica de Enfermagem do Centro do Saúde "Geraldo de Paula Souza". 
E - Escolas de Enfermagem, no seu setor de Diretoria:
a) da Universidade de São Paulo;
b) Faculdade Paulista de Enfermagem;
c) Faculdade Adventista de Enfermagem;
d) Faculdade de Enfermagem São José - Santa Casa . magem.

F - INPS - no seu setor de Assessoria Técnica de Enfer-

G - Hospitais de Ensino - no seu setor de Chefia de Enfermagem:
a) Hospital das Clínicas;
b) Hospital São Paulo;
c) Hospital dos Servidores Públicos de São Paulo;
d) Hospital Matarazzo;
e) Hospital da Santa Casa de Misericórdia.

\section{5 - População da pesquisa}

\subsection{1 - Determinação do Tamanho da População:}

A população da pesquisa foi determinada por escolha intencional, e em se tratando de um levantamento total, ela é constituída por todas as unidades da população, isto é, pelas 27 enfermeiras que executam funções consideradas representativas no universo delimitado, dentro das estratificações convencionadas.

\subsection{2 - Critério de Escolha}

O critério adotado para a escolha da população foi baseado nos seguintes fatores:

a) tempo disponível que condicionou o universo da pesquisa e o tipo de escolha da população;

b) representatividade das unidades da população que con dicionou a seleção dos estratos do universo;

c) alcance dos resultados esperados, a partir da representatividade da população escolhida.

\subsection{3 - Categorização da População}

A - Critério para categorização: existência ou inexistência de experiência prévia ou atual das enfermeiras. 


\section{B - Divisão:}

- Enfermeiras com experiência profissional prévia ou atual com o Técnico de Enfermagem.

- Enfermeiras sem experiência profissional prévia ou atual com o Técnico de Enfermagem.

C - Classificação dentro da categoria: dentro da categoria foi classificada a população por extratos de universo, segundo a seguinte convenção:

- CLASSE a: enfermeiras que atuam na regulamentação do ensino do Técnico de Enfermagem, em exercício na Secretaria da Educação .

- CLASSE b: enfermeiras que atuam na regulamentação do exercício profissional do Técnico de Enfermagem, em exercício na Secretaria da Saúde.

- CLASSE c: enfermeiras que influem na elaboração de currículos de cursos de Técnicos de Enfermagem, em exercício nas Escolas de Enfermagem do Distrito de São Paulo.

- CLASSE d: enfermeiras que atuam em campos de estágic do Técnico de Enfermagem, em exercício nos Hospitais de Ensino de Escolas de Enfermagem do Distrito de São Paulo.

- CLASSE e: enfermeiras que influem na prática do exercício profissional do Técnico de Enfermagem, em exercício na Faculdade de Saúde Pública da USP, em Escolas de Enfermagem e na Secretaria de Estado da Saúde do Estado de São Paulo.

\section{6 - Definição das Variáveis}

\subsection{1 - Categorização}

A - Variáveis dependentes: são representadas por dois elementos da pesquisa:

a) conhecimentos específicos das enfermeiras sobre o Técnico de Enfermagem; presume-se que apresentariam mutações, de conformidade com a existência ou inexistência de experiência profissional prévia das enfermeiras com o mesmo Técnico;

b) conduta manifesta das enfermeiras, no sentido de opinarem favorável ou não favoravelmente à utilização do Técnico de Enfermagem em saúde pública; presume-se que estaria sujeita à influência dos fatores experiência prévia das enfermeiras e dos seus conhecimentos específicos relativamente ao Técnico de Enfermagem. 
B - Variáveis independentes: são constituídas por dois tipos di: elementos:

a) Elementos de relação causal:

a.1 - experiência profissional prévia da enfermeira com o Técnico de Enfermagem;

a.2 - grau de conhecimentos específicos das enfermeiras, aqui atuando, segundo suposição, como fator de variabilidade da conduta.

b) Elemento de relação explicativa: sua função na pesquisa é de meia indicação de categoria da população pesquisada.

\subsection{2 - Especificação das Áreas das Variáveis}

\subsubsection{1 - Variáveis Dependentes}

A - Área dos conhecimentos específicos das enfermeiras relativos ao Técnico de Enfermagem:

a) Área do conhecimento da existência da categoria.

b) Área do conhecimento relativo à sua formação: ensino;

- da existência ou inexistência de regulamentação do seu

- do conteúdo do currículo do seu curso de formação.

c) Área do conhecimento das suas atribuições:

- da existência ou inexistência de estudos que tenham procurado especificar as atribuições da categoria;

- da área em que se teria verificado tais especificações;

- percepção das atividades que o Técnico de Enfermagem poderia executar no campo da enfermagem de saúde pública.

d) Área do conhecimento da existência ou inexistência de regulamentação do seu exercício profissional.

e) Área do conhecimento do nível da estrutura organizacional dos serviços de saúde pública da Secretaria de Estado da Saúde de São Paulo, em que poderia ser localizado o Técnico de Enfermagem.

B - Área da conduta manifesta das enfermeiras, no sentido te opinarem favorável ou não favoravelmente: 
a) Quanto à existência ou inexistência, no Estado de São Paulo, de justificativas para a utilização do Técnico de Enfermagem nr, campo da saúde pública.

b) Quantu à prioridade que seria atribuida à categoria Técnico de Enfermageı̊ em relação à categoria Auxiliar de Enfermagem, para trabalho de enfermagem de saúde pública.

c) Quanto às ba:reiras à utilização do Técnico de Enfermagem no campo da enfermı́gem de saúde pública.

d) Quanto a fatores que facilitariam essa utilização.

e) Quanto ao caráter às agendamento da discussão do problema "Utilização do Técnico dc Enfermagem no Campo da Enfermagem de Saúde Pública":

— de indicação ou não indiçção dessa discussão;

- de proposição desse agendaısento à solução do problema da categoria Enfermeiro na estruturaçän administrativa da Secretaria da Saúde;

- de apresentação espontânea do problema para discussão;

— da nomeação dos aspectos do problema que deverão ser estudados.

\subsubsection{2 - Variáveis Independentes}

A - Elementos de relação causal:

a) Existência ou inexistência de experiência profissional prévia ou atual das enfermeiras com o Técnico de Enfermagem.

b) Grau de conhecimentos específicos identificado nas diversas áreas:

b.1 - conhecimentos suficientes;

b.2 - conhecimentos não suficientes.

B - Elemento de relação explicativa:

a) Classe das enfermeiras conforme relacionamento ao ensino, estruturação da carreira e exercício profissional do Técnico de Enfermagem.

b) Instituição em que essa função é exercida. 
4 - Organização do Formulário com os Indicadores para Mensuração das Respostas

\section{1 - Variáveis Dependentes}

\subsection{1 - Conhecimentos Especificos Relativos ao Técnico de Enfer- magem:}

A - Conhecimento da existência da categoria de Técnico de Enfermagem:

- Q.2 - A resposta deverá ser "sim" — com valor $S$ (suficiente) e "não" com valor $N S$ (não suficiente).

- Q.3 - A resposta deverá ser a indicação de uma das sugestões, sendo a $1 .^{a}$ considerada $S$ (suficiente) e as demais $N S$ (não suficiente)

B - Conhecimento relativo ao seu ensino:

a) conhecimento da existência ou inexistência de dispositivo legal que regulamenta o ensino do Técnico de Enfermagem:

- Q.4 - A resposta deverá ser "sim" com valor $S$ (suficiente) e "não" com valor $N S$ (não suficiente).

b) conhecimento do conteúdo do currículo do curso de Técnico de Enfermagem:

- Q.5 - A resposta deverá ser "sim" com valor $S$ (suficiente) ou “não", com valor $N S$ (não suficiente).

- Q.6 - A resposta deverá ser a nomeação do elenco, com valor $S$ (suficiente) ou a declaração de "não sei”, com valor $N S$ (não suficiente).

C - Conhecimento das atribuições do Técnico de Enferma. gem:

a) conhecimento da existência de estudos que tenham procurado especificar as atribuições do Técnico:

- Q.7 - A resposta deverá ser a opção de uma das sugestões, sendo a $10^{\mathrm{a}}$ considerada $S$ e as demais $N S$.

b) conhecimento da área em que teriam sido especificadas as atribuições :

- Q.8 - A resposta será a opção de uma das sugestões, sendo a $1 .^{q}$ considerada $S$ (suficiente) e as demais $N S$ (não suficiente). 
D - Conhecimento da existência ou inexistência de dispositivo legal que regulamenta o exercício profissional do Técnico de Enfermagem:

- Q.9 - A resposta será “sim", com valor $S$ (suficiente) e “não" ou "não sei”, com valor $N S$ (não suficiente).

E - Percepção das atividades que o Técnico de Enfermagem poderia executar no campo da enfermagem de saúde pública:

- Q.15 - A resposta deverá ser a indicação das atividades apresentadas em relação anexa ao Formulário sendo a indicação de todas considerada $M S$ (muito suficiente) e a de algumas, com gradações de $M S$ e $N S$.

F - Conhecimento do nível da estrutura organizacional dos serviços de saúde pública da Secretaria de Estado da Saúde de São Paulo, em que poderia ser localizado o Técnico de Enfermagem:

- Q.17 - A resposta deverá ser a indicação de uma das sugestões, sendo a indicação da $3 .^{a}$ considerada $S$ (suficiente) e a das demais $N S$ (não suficiente).

\subsection{2 - Conduta das Enfermeiras no Sentido de Opinarem Favo- rável ou não Favoravelmente:}

A - Quanto à existência ou inexistência, no Estado de São Paulo, de justificativas e de suas razões para a utilização do Técnico de Enfermagem no campo da saúde pública:

- Q.14 - A resposta deverá ser “sim”, com valor $F$ (favorável) ou "não", com valor $N F$ (não favorável). O valor $F$ terá gradações de $M F$ e $P F$, (muito e pouco favorável).

B - Quanto à prioridade que seria atribuída à categoria Técnico de Enfermagem em relação à categoria Auxiliar de Enfermagem para o trabalho de enfermagem de saúde pública:

- Q.16 - A resposta indicará uma das sugestões: a indicação da $1 .^{\mathrm{a}}$ terá valor $M F$ (muito favorável) e a das demais $P F$ (pouco favorável).

C - Quanto a barreiras existentes em relação à utilização do Técnico de Enfermagem no campo da enfermagem de saúde pública:

— Q.18 - A resposta deverá ser "sim", com valor $M F$ (muito favorável) ou "não", com valor $P F$ (pouco favorável). 
D - Quanto a fatores que facilitariam a utilização do Técnic1) de Enfermagem no campo da enfermagem de saúde pública:

— Q.21 - A resposta será “sim", com valor $M F$ ou "não", com valor $P F$, (muito e pouco favorável).

- Q.22 - A resposta será indicação de sugestões cuja valorização será feita a posteriori.

E - Quanto ao caráter do agendamento da discussão do problema "Utilização do Técnico de Enfermagem no Campo da Enfermagem de Saúde Pública":

a) da indicação ou não indicação dessa discussão:

- Q.23 - A resposta “sim" terá valor $M F$ e as demais $N F$.

b) da proposição desse agendamento à solução do problema da categoria Enfermeiro na estruturação da Secretaria de Estado da Saúde do Estado de São Paulo:

- Q.24 - A resposta "não" terá valor $M F$ e as demais $P F$ (muito e pouco favorável).

c) da apresentação espontânea do problema para discussão:

— Q.25 - A resposta “não" terá valor $M F$ e as demais $P F$.

d) da nomeação dos aspectos do problema que deverão ser estudados:

- Q.26 - A resposta "sim" terá valor $F$ com gradações de $M F, R F$ e $P F$. As demais com valor $P F$.

\section{2 - Variváveis Independentes}

\subsection{1 - Elementos de Relação Causal:}

A - Existência ou inexistência de experiência profissional prévia ou atual das enfermeiras com o Técnico de Enfermagem.

- Q.10 - A resposta indicará a categoria da entrevistada.

- Q.11 - A resposta indicará a categoria da entrevistada.

- Q.12 - A resposta indicará a categoria da entrevistada. 
B - Qualidade suficiente ou não suficiente dos conhecimentos específicos, identificada nas diversas áreas:

$-\mathbf{Q . 2}$

$-Q .3$

$-\mathbf{Q . 4}$

$-\mathbf{Q . 5}$

$-Q .6$

$-Q .7$

$-\mathbf{Q . 8}$

- Q.9

$-\mathrm{Q} .15$

$-\mathbf{Q} .17$

4.2.2 - Elementos de Relação Explicativa Constituidos Pelas Funções Profissionais da População Escolhida e Pelos Locais em que as Mesmas são Exercidas:

- Q.1 - A resposta indicará a classe da entrevistada.

\section{3 - Observações}

- Q.13 - Incluída no formulário para reforçar a área dos conhecimentos sobre as atribuições do Técnico de Enfermagem, poderá ser excluída na apresentação dos dados.

- Q.20 - Incluída no formulário para fornecer dados para o desenvolvimento de um dos aspectos do Tema Central (não ser computada juntamente com as demais questões).

5 - Programação de Estatística

\section{1 - Método de Processamento de Dados}

O processamento de dados será feito manualmente, pela res. ponsável da pesquisa.

\subsection{2 - Critério para Mensuração dos Valores das Variáveis:}

As respostas das questões do Formulário serão medidas segundo uma escala de valores qualitativos e quantitativos.

\subsubsection{1 - Valores Qualitativos:}

I - Variáveis Dependentes: 
A - Conhecimentos: terá uma escala composta de 4 valores:

- MS - muito suficiente

- RS - regularmente suficiente

- PS - pouco suficiente

- NS — não suficiente.

B - Conduta: identificada nas opiniões conforme uma escala de 4 valores:

- MF - muito favorável

- RF - regularmente favorável

- PF - pouco favorável

- NF - não favorável.

\section{II - Variáveis Independentes:}

A - Categoria das enfermeiras: escala composta pela definição de duas categorias:

a) enfermeira com experiência;

b) enfermeira sem experiência.

B - Classe: escala composta de 5 classes:

a) enfermeiras que atuam na regulamentação do ensino do Técnico de Enfermagem;

b) enfermeiras que atuam na regulamentação do exercício profissional do Técnico de Enfermagem;

c) enfermeiras que influem na elaboração do currículo do curso de Técnico de Enfermagem;

d) enfermeiras que atuam em campos de estágio do Técnico de Enfermagem;

e) enfermeiras que influem na prática do exercício profis sional do Técnico de Enfermagem.

\subsubsection{2 - Valores Quantitativos}

As respostas receberão um peso positivo ou negativo, de acordo com a relação exposta na TABELA $I$.

\subsection{3 - Indicadores Globais}

Será a média ponderada das respostas, quer para as classes, quer para as categorias, dentro das variáveis "conhecimentos" E "conduta manifesta". 


\subsection{4 - Planejamento da Apresentação Tabular dos Resultados}

Na apuração dos dados está prevista a utilização das seguintes tabelas:

1 - tabela composta para medir a distriłuição de freqüência das categorias e classes da população entrevistada;

2 - tabela compostiı, de correlação, ou mista, para medir a distribuição parcial de conhecimentos da população entrevistada, condicionados aos fatores classe e categoria dessa mesma população.

3 - tabela composta, de correlação, ou mista, para medir a distribuição parcial de opiniões da população entrevistada, condicionadas aos fatores classe e categoria dessa mesma população;

4 - tabela composta, de correlação, para medir a distribuição total de freqüência das opiniões da população entrevistada, condicionada aos fatores conhecimento, classe e categoria dessa mesma população.

\section{EXECUÇÃO DA PESQUISA}

Elaborado o plano da pesquisa, passamos à fase da execução, em que se pode distinguir 4 aspectos:

\section{1 - Plano de Operações - que constou das seguintes etapas:} formulários;

— orientação de 2 colegas colaboradores na aplicação dos

- divisão do trabalho;

- agendamento das entrevistas.

\section{2 - Coleta de Dados}

Feita através da aplicação dos Formulários. Cabe dizer aqui que, das 29 entrevistas planejadas, duas não se realizaram, por estarem as enfermeiras a serem entrevistadas ausentes de São Paulo por tempo indeterminado.

As 27 entrevistas feitas decorreram sem que nada houvesse de anormal, ressaltamos apenas, por justiça, o bom acolhimento geral que as enfermeiras entrevistadas nos dispensaram.

O tempo total gasto para a aplicação dos Formulários foi de duas semanas, em virtude de termos de nos condicionar ao tempo disponível das entrevistadas. Contudo, o tempo médio gasto na aplicação propriamente dita, foi de 15 minutos, aproximadamente.

\section{3 - Revisão dos Formulários - Crítica}

Alguns reparos básicos estão ligados ao fator tempo, principalmente o destinado à elaboração do plano da pesquisa, o qual se limitou a apenas uma semana. Este fato condicionou as seguintes falhas: 


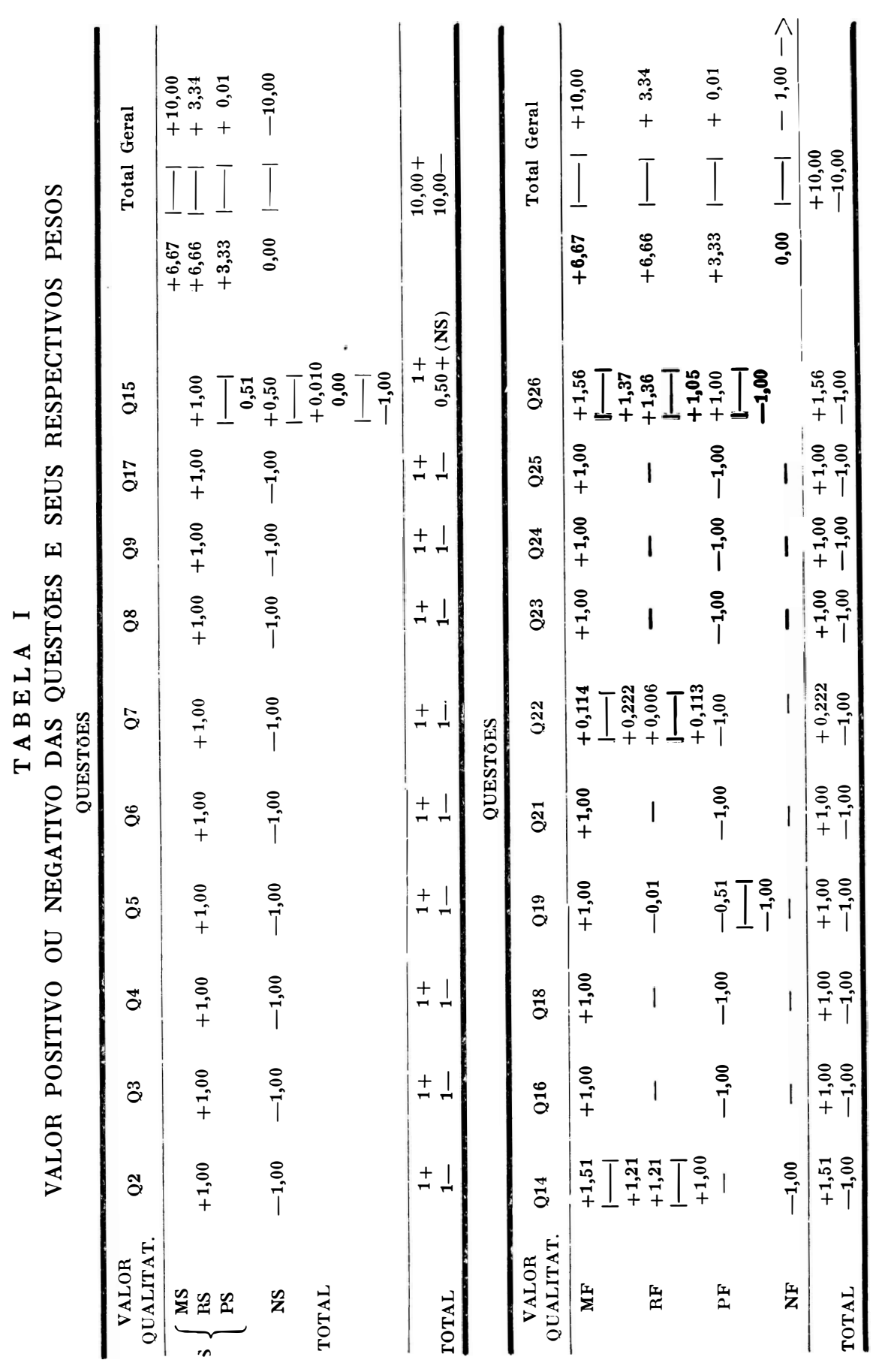


a) limitação da população pesquisada, cujo tamanho não teria nem mesmo sido significativo, não fosse a alta representatividade das entrevistadas escolhidas;

b) limitação das áreas específicas das variáveis definidas, com exclusão de aspectos de muito interesse, como por exemplo, o da identificação das atribuições atualmente exercidas pelos Técnicos de Enfermagem existentes no Distrito de São Paulo;

c) ausência de pré-teste do Formulário; esta falha foi uma das mais lamentáveis, pois, sabe-se, por razões óbvias, quanto se consegue aperfeiçoar um Formulário através do pré-teste; apontamos, a seguir, as falhas mais graves que nos foi possível identificar no Formulário:

T A B E L A I I

FALHAS DO FORMULÁRIO, SEGUNDO AS QUESTÕES, OS OBJETIVOS E A TÉCNICA DE ELABORAÇÃO

\begin{tabular}{|c|c|c|}
\hline Questões & $\begin{array}{c}\text { Relatório ao Objetivo } \\
\text { da Pesquisa }\end{array}$ & Relat. à Técnica de Elabor. \\
\hline 1 & - não significativa & - \\
\hline 2 & - não significativa & 一 \\
\hline 5 & - & $\begin{array}{l}\text { - possibilitou } 2 \text { respostas vá- } \\
\text { lidas: a } 3 .^{a} \text { sugestão englo- } \\
\text { ba tanto a } 1 .^{\mathrm{a}} \text { como a } 2 .^{\mathrm{a}} \\
\text { sugestões. }\end{array}$ \\
\hline 9 & 一 & $\begin{array}{l}\text { - mal redigida: o significado } \\
\text { pretendido era "estudadas" } \\
\text { em vez de "especificadas". }\end{array}$ \\
\hline 14 & -- pouco significativa & - \\
\hline 15 & - não significativa & - \\
\hline 18 & - & $\begin{array}{l}\text { - mal redigida }- \text { dificultou a } \\
\text { interpretação. }\end{array}$ \\
\hline 20 & - & $\begin{array}{l}\text { - incluída após a elaboração } \\
\text { do Formulário; ficou mal } \\
\text { redigida, exigindo interpre- } \\
\text { tação complementar. }\end{array}$ \\
\hline 21 & - & $\begin{array}{l}\text { - mal redigida, exigindo in- } \\
\text { terpretação complementar. }\end{array}$ \\
\hline 22 & & $\begin{array}{l}\text { - mal redigida, exigindo mui- } \\
\text { ta complementação para ser } \\
\text { compreendida. }\end{array}$ \\
\hline $\begin{array}{l}25,26 \\
27 \text { e } 28\end{array}$ & & - mal redigida e repetitivas. \\
\hline
\end{tabular}


Anteriormente à aplicação do Formulário fizemos algumas correções emergenciais, manuscritamente, o que prejudicou a estética di sua apresentação. Eliminamos as seguintes questões:

- Q.1, Q.2, Q.14 e Q.15.

Acrescentamos uma questão, e a numeração foi modificada como segue:

T A B E L A I I I

NUMERAÇÃO DOS FORMULÁRIOS - PRIMITIVA E ATUAL

Numeração Numeração Atual Numeração Numeração Atual Primitiva Correspondente Primitiva Correspondente

\begin{tabular}{rrrl}
\hline 3 & 1 & 16 & 14 \\
4 & 2 & 17 & 15 \\
5 & 3 & 18 & 16 \\
6 & 4 & 19 & 17 \\
7 & 5 & 20 & 18 \\
8 & 6 & 21 & 19 \\
9 & 7 & 22 & 20 \\
10 & 8 & 23 & 21 \\
11 & 9 & 24 & 22 \\
12 & 10 & 25 & 23 \\
13 & 11 & 26 & 24 \\
& & 27 & 25 \\
& & 28 & 26 \\
\hline
\end{tabular}

\section{4 - Apuração e Análise dos Resultados}

Conforme planejáramos, usamos 5 tabelas na apuração dos resultados. Em virtude da nossa inexperiência no assunto e da dificuldade de assessoria técnica em estatística, a etapa mais dificultosa e demorada deste trabalho foi a da apuração e análise dos resultados, consumindo um tempo desproporcional (3 semanas) ao tamanho da pesquisa. 
Os resultados podem ser resumidos nos seguintes aspectos (tab. IV) :

A - Categorização e classificação das entrevistadas:

- 14 entrevistadas na categoria com experiência, com a seguinte distribuição:

- 3 na classe a

- 2 na classe $b$

- 1 na classe c

- 6 na classe $d$

- 2 na classe e

- 13 entrevistadas na categoria sem experiência, com a seguinte distribuição:

- 1 na classe a

- 4 na classe c

- 2 na classe $d$

- 6 na classe e

B - Distribuição da freqüência dos conhecimentos parciais das enfermeiras entrevistadas, segundo as classes e categorias (Tabela V).

B.1 - Média geral da distribuição dos conhecimentos:

a) Distribuição total:

- valor quantitativo: 5,11

- valor qualitativo: R.S. (regularmente suf.)

b) Distribuição parcial segundo a classe e valores:

\begin{tabular}{|c|c|c|c|}
\hline Classe & & Valor qualit. & Valor quantit. \\
\hline a ... & $\ldots \ldots \ldots c c$ & M.S. & 8,50 \\
\hline b .. & $\begin{array}{llllll} & \ldots & \ldots & \ldots & \ldots & \ldots\end{array}$ & R.S. & 5,58 \\
\hline c .. & $\begin{array}{llllll} & \ldots & \ldots & \ldots & \ldots & \ldots\end{array}$ & R.S. & 3,41 \\
\hline d .. & $\begin{array}{lllll} & \ldots & \ldots & \ldots & \ldots\end{array}$ & P.S. & 3,24 \\
\hline e .. & $\begin{array}{lllll}\ldots & \ldots & \ldots & \ldots & \ldots\end{array}$ & R.S. & 4,75 \\
\hline
\end{tabular}




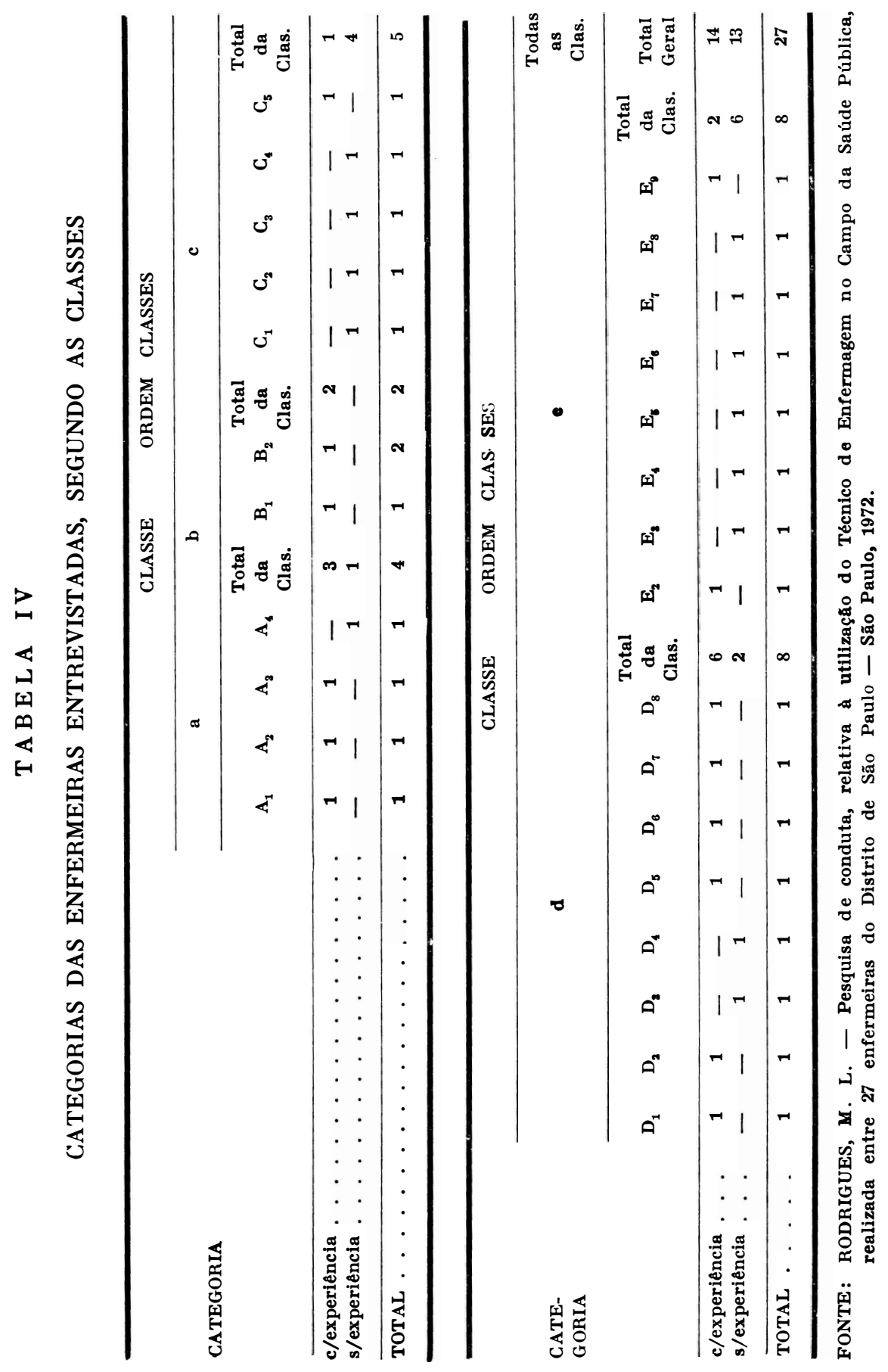




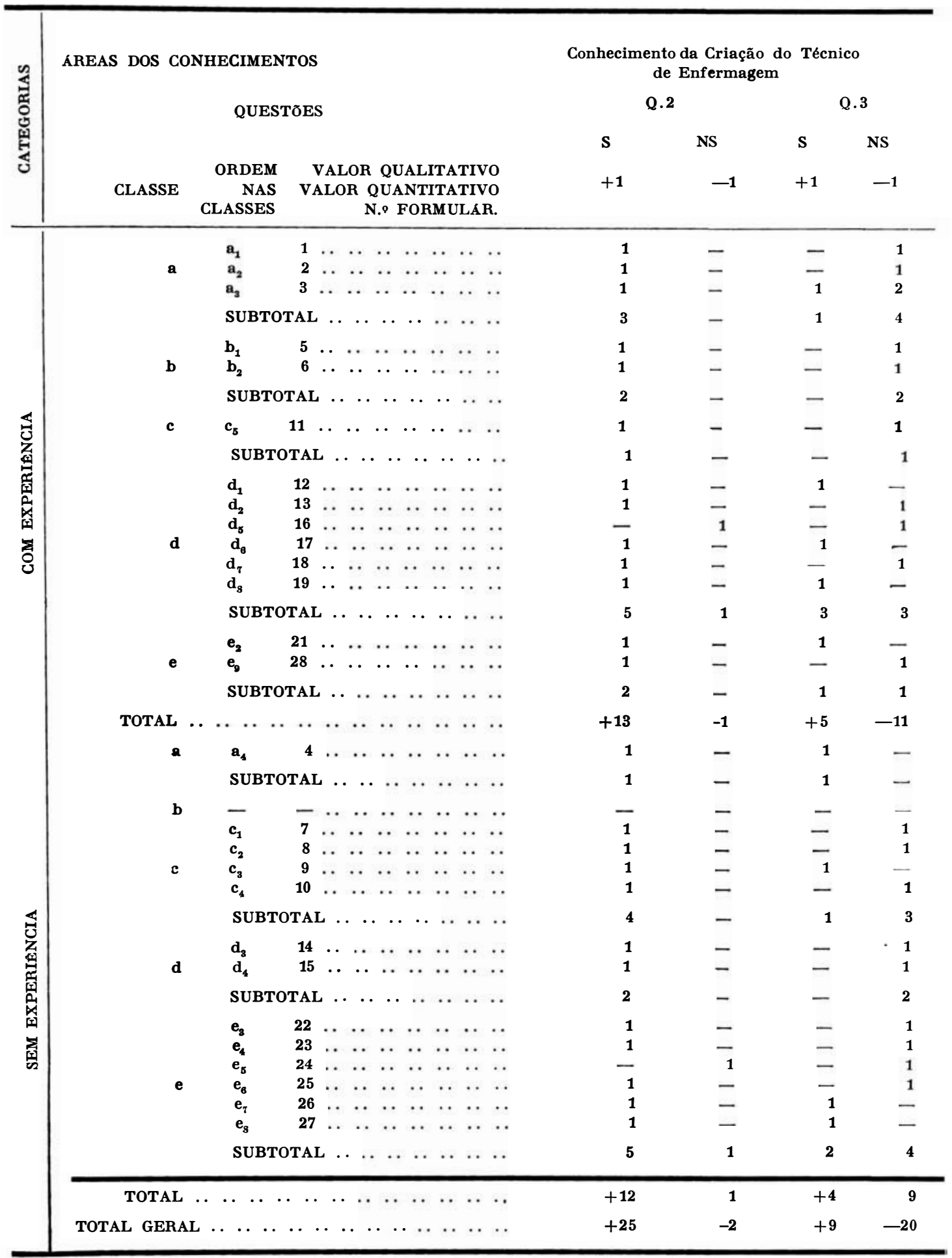

FONTE: RODRIGUES, M. L. - Pesquisa da conduta manifesta de 27 enfermeiras, sobre a utilização do

LEGENDA: a, b, c, d, e = classes das entrevistadas.

$$
\begin{aligned}
\mathbf{Q} & =\text { questão. } \\
\mathbf{S} & =\text { suficiente. } \\
\mathbf{N S} & =\text { não suficiente. }
\end{aligned}
$$


TABELA $V$

DISTRITO DE SÃO PAULO, ENTREVISTADAS RELATIVAMENTE À UTILIZAÇÃO AS CLASSES E CATEGORIAS - SÃO PAULO - 1972

Conhecimento Sobre o Ensino do Técnico de Enfermagem

Q.4
Conhecimento das Atribuições do Técnico de Enfermagem

Q.7

Q.8

Q.15

\begin{tabular}{|c|c|c|c|c|c|c|c|c|c|c|c|}
\hline 1 & - & 1 & - & 1 & - & 1 & - & 1 & - & 1 & - \\
\hline 1 & - & 1 & - & 1 & - & 1 & - & 1 & - & 1 & - \\
\hline 1 & - & 1 & - & 1 & - & 1 & - & 1 & 1 & 1 & - \\
\hline 3 & - & 3 & - & 3 & - & 3 & - & 3 & 1 & 3 & - \\
\hline 1 & - & 1 & - & 1 & - & 1 & - & - & 1 & - & $+0,17$ \\
\hline 1 & - & 1 & - & 1 & - & 1 & - & 1 & - & 1 & - \\
\hline 2 & - & 2 & - & 2 & - & 2 & - & 1 & 1 & 1 & $+0,17$ \\
\hline 1 & - & 1 & - & 1 & - & 1 & - & - & 1 & 1 & - \\
\hline 1 & - & 1 & - & 1 & - & 1 & - & - & 1 & 1 & - \\
\hline- & 1 & - & 1 & - & 1 & - & 1 & - & 1 & 0,90 & - \\
\hline 1 & - & - & 1 & - & 1 & - & 1 & - & 1 & 0,80 & - \\
\hline 1 & - & 1 & - & 1 & - & 1 & - & 1 & - & 1,00 & - \\
\hline 1 & - & 1 & - & 1 & - & - & 1 & - & 1 & 1,00 & - \\
\hline- & 1 & 1 & - & 1 & - & - & 1 & - & 1 & - & $+0,42$ \\
\hline- & 1 & 1 & - & 1 & - & - & 1 & - & 1 & 0,91 & - \\
\hline 3 & 3 & 4 & 2 & 4 & 2 & 1 & 5 & 1 & 5 & 4,61 & $+0,42$ \\
\hline 1 & - & 1 & - & 1 & - & 1 & - & 1 & - & 1,00 & - \\
\hline 1 & - & - & 1 & - & 1 & - & 1 & - & 1 & 0,80 & - \\
\hline 2 & - & 1 & 1 & 1 & 1 & 1 & 1 & 1 & 1 & 1,80 & - \\
\hline+11 & -3 & +11 & -3 & +11 & -3 & +8 & -6 & +6 & -9 & $+11,41$ & $-0,59$ \\
\hline 1 & - & 1 & - & 1 & - & 1 & - & 1 & - & 1 & - \\
\hline 1 & - & 1 & - & 1 & - & 1 & - & 1 & - & 1 & - \\
\hline - & - & - & - & - & - & - & - & - & - & - & - \\
\hline 1 & - & 1 & - & 1 & - & - & 1 & - & 1 & 0,92 & - \\
\hline 1 & - & 1 & - & 1 & - & 1 & - & 1 & - & 0,90 & - \\
\hline 1 & - & - & 1 & - & 1 & 1 & - & - & 1 & 0,62 & - \\
\hline- & 1 & - & 1 & - & 1 & 1 & - & - & 1 & 0,90 & - \\
\hline 3 & 1 & 2 & 2 & 2 & 2 & 3 & 1 & 1 & 3 & 3,34 & - \\
\hline 1 & - & 1 & - & 1 & - & 1 & - & 1 & - & 0,80 & - \\
\hline 1 & - & 1 & - & 1 & - & - & 1 & - & 1 & 0,80 & - \\
\hline 2 & - & 2 & - & 2 & - & 1 & 1 & 1 & 1 & 1,60 & - \\
\hline 1 & - & 1 & - & 1 & - & 1 & - & - & 1 & 1,00 & - \\
\hline 1 & - & 1 & - & 1 & - & 1 & - & 1 & - & 0,73 & - \\
\hline 1 & - & 1 & - & 1 & - & - & 1 & - & 1 & 1,00 & - \\
\hline 1 & - & 1 & - & 1 & - & 1 & - & 1 & - & 0,90 & - \\
\hline 1 & - & 1 & - & 1 & - & 1 & - & - & 1 & 1,00 & - \\
\hline 1 & - & 1 & - & 1 & - & - & 1 & - & 1 & 1,00 & - \\
\hline 6 & - & 6 & - & 6 & - & 4 & 2 & 2 & 4 & 5,63 & - \\
\hline+12 & 1 & +11 & 2 & +11 & 2 & +9 & 4 & +5 & 8 & $+11,57$ & - \\
\hline+23 & -4 & +22 & -5 & +22 & -5 & +17 & -10 & +11 & -17 & $+22,98$ & $-0,59$ \\
\hline
\end{tabular}

Técnico de Enfermagem no Campo da Saúde Pública - São Paulo, 1972. 
Conhecimento Sobre o Exercício Profissional do Técnico de Enfermagem

Q.9

Q.17
TO T A L

\begin{tabular}{llr} 
NS & $S$ & NS \\
-1 & $+1,00$ & $-1,00$ \\
\hline $\mid \frac{10, \mid}{10,00}$ & $-10,00$
\end{tabular}

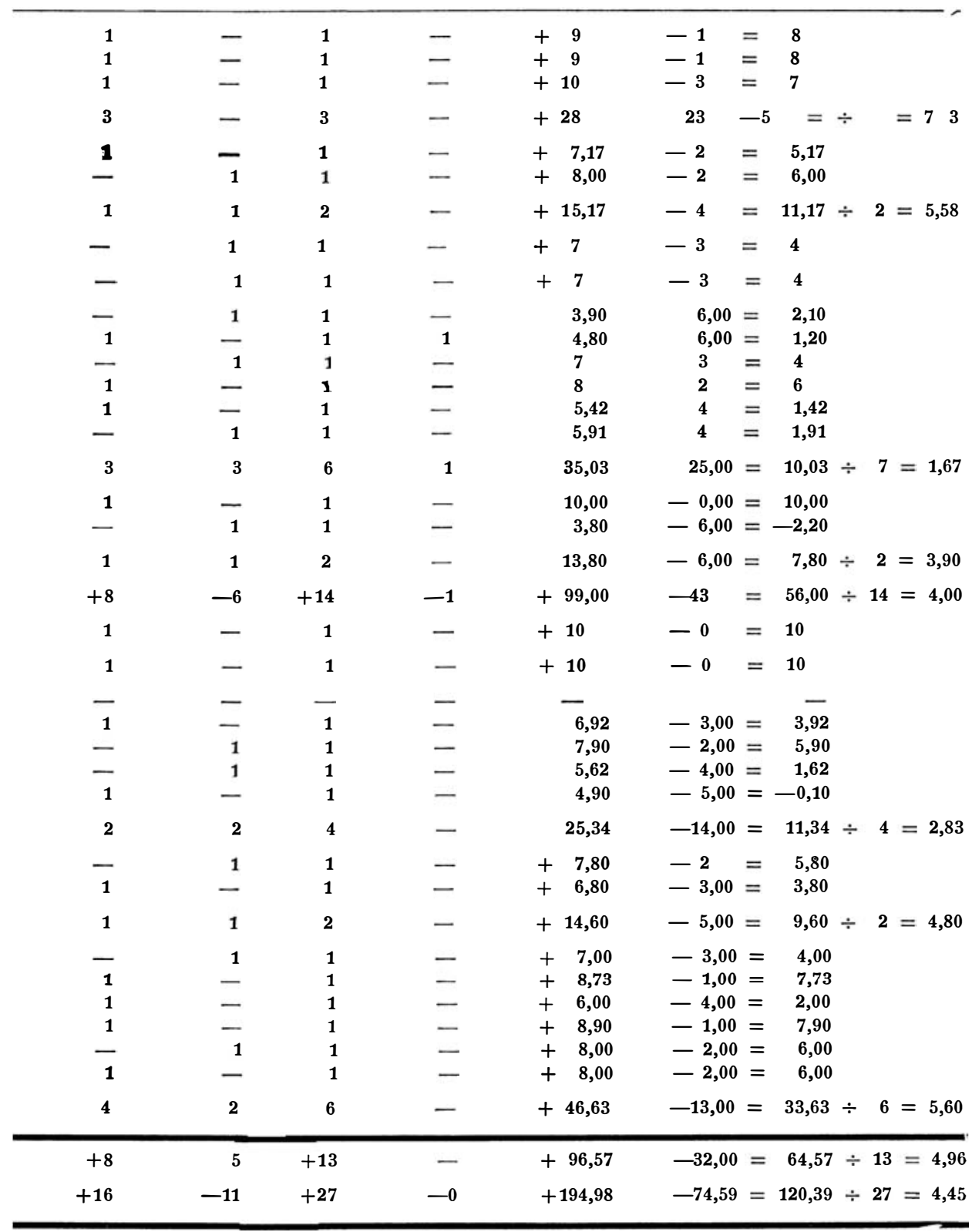


C - Distribuição de freqüência das opiniões parciais das enfermeiras entrevistadas, segundo as classes e categorias (Tabela VI) :

C.1 - Média geral da distribuição de opiniões:

a) Distribuição geral:

a.1 - Valor qualitativo: R.F. (regularmente favorável)

a.2 - Valor quantitativo: 4,177

b) Distribuição parcial segundo classe e valores:

\begin{tabular}{ccccccccc}
\multicolumn{4}{c}{ Classe } & & & Valor qualitat. & Valor quantitat. \\
a & $\ldots$ & $\ldots$ & $\ldots$ & $\ldots$ & $\ldots$ & $\ldots$ & P.F. & $\mathbf{2 , 1 2}$ \\
b & $\ldots$ & $\ldots$ & $\ldots$ & $\ldots$ & $\ldots$ & $\ldots$ & P.F. & $\mathbf{0 , 1 9}$ \\
c & $\ldots$ & $\ldots$ & $\ldots$ & $\ldots$ & $\ldots$ & $\ldots$ & M.F. & $\mathbf{7 , 4 5}$ \\
d & $\ldots$ & $\ldots$ & $\ldots$ & $\ldots$ & $\ldots$ & $\ldots$ & R.F. & $\mathbf{5 , 1 7}$ \\
e & $\ldots$ & $\ldots$ & $\ldots$ & $\ldots$ & $\ldots$ & $\ldots$ & R.F. & $\mathbf{5 , 0 0}$
\end{tabular}

D - Distribuição de freqüência das opiniões das enfermeiras entrevistadas, segundo os conhecimentos totais, segundo as classes e categorias (Tabela VII):

D.1 - Média geral das distribuições das opiniões segundo a média de distribuição dos conhecimentos:

Média geral da conduta

Média geral dos conhecimentos

valor qual.

Valor quant. Valor qualit. Valor quantit.
R.F. . . . . .
4,177
R.S.
5,80

D.2 - Média parcial da distribuição das opiniões segundo a média parcial da distribuição dos conhecimentos:

Variav. Conduta Conhecimentos

\begin{tabular}{|c|c|c|c|c|c|c|c|c|c|}
\hline \multicolumn{5}{|c|}{ Classes } & Val. & qual. & Val. quant. & Val. qual. & Val. quant \\
\hline $\mathbf{a}$ & . & & & .. & & P.F. & 2,12 & M.S. & 8,50 \\
\hline b & . & & & . & & P.F. & 0,19 & R.S. & 5,50 \\
\hline c & . & & & • & & M.F. & 7,45 & R.S. & 3,48 \\
\hline d & . & & - & & . & R.F. & 5,17 & P.S. & 3,24 \\
\hline e & . & & * & . & . & R.F. & 5,00 & ?.S. & 4,75 \\
\hline
\end{tabular}

E - Média geral da distribuição dos conhecimentos segundo a categoria:

Com experiência Sem experiência

Valor qual. Valor quant. Valor qual. Valor quant.
R.S. . . . .
4,43
R.S.
5,80 
F - Média geral de distribuição de opiniões segundo a categoria:

Com experiência

Valor qual.

R.F.
Valor quant. 3,62
Sem experiência

Valor qual. Valor quant.

R.F.

4,735

4 - CONCLUSÕES :

4.1 - Conclusão parcial sobre a Hipótese 1: a relação de efeito entre grau de conhecimento das enfermeiras entrevistadas e sua categoria, não foi comprovada (efeito direto)

4.2 - Conclusão parcial sobre a hipótese 2: a relação de efeito entre conduta das entrevistadas e sua categoria não foi comprovada (efeito direto)

4.3 - Conclusão parcial sobre a hipótese 3: a relação de efeito direto entre o grau de conhecimento das enfermeiras entrevistadas e a sua conduta foi comprovada.

\section{4 - Conclusão final:}

4.4.1 - A conduta de 27 enfermeiras do Distrito de São Paulo, em exercício de funções consideradas representativas em relação ao Técnico de Enfermagem, entrevistadas relativamente à utilização desse técnico no campo da saúde pública, pode ser consideradà regularmente favorável.

4.4.2 - Considerando que os fatores "experiência profissional prévia ou atual" e "grau de conhecimentos" aparentam ter influências diferentes, sendo que:

a) o fator "experiência" parece não ter relação direta de sentido com a conduta, nem com os conhecimentos, aparentando ter uma relação de sentido neutra (contudo, os resultados provavelmente nem mesmo se relacionam);

b) o fator grau de conhecimento aparentemente tem uma relação de sentido direta com a conduta;

Cioncluimos que:

a) o fator “experiência profissional prévia ou atual” não influiu nem sobre a conduta, nem sobre os conhecimentos das enfermeiras entrevistadas;

b) o grau de conhecimentos R.S. (regularmente suficiente) das enfermeiras entrevistadas influiu na conduta dessas enfermeiras no sentido de serem R.F. (regularmente favoráveis) à utilização do técnico de enfermagem no campo da saúde pública. 
DISTRIBUIÇÃO DA FREQUUENCIA DA CONDUTA (OPINIŐES) DE 27 ENFERMEIRAS DO QUESTÕES

VALOR OUANLITATIVO TITATIVO

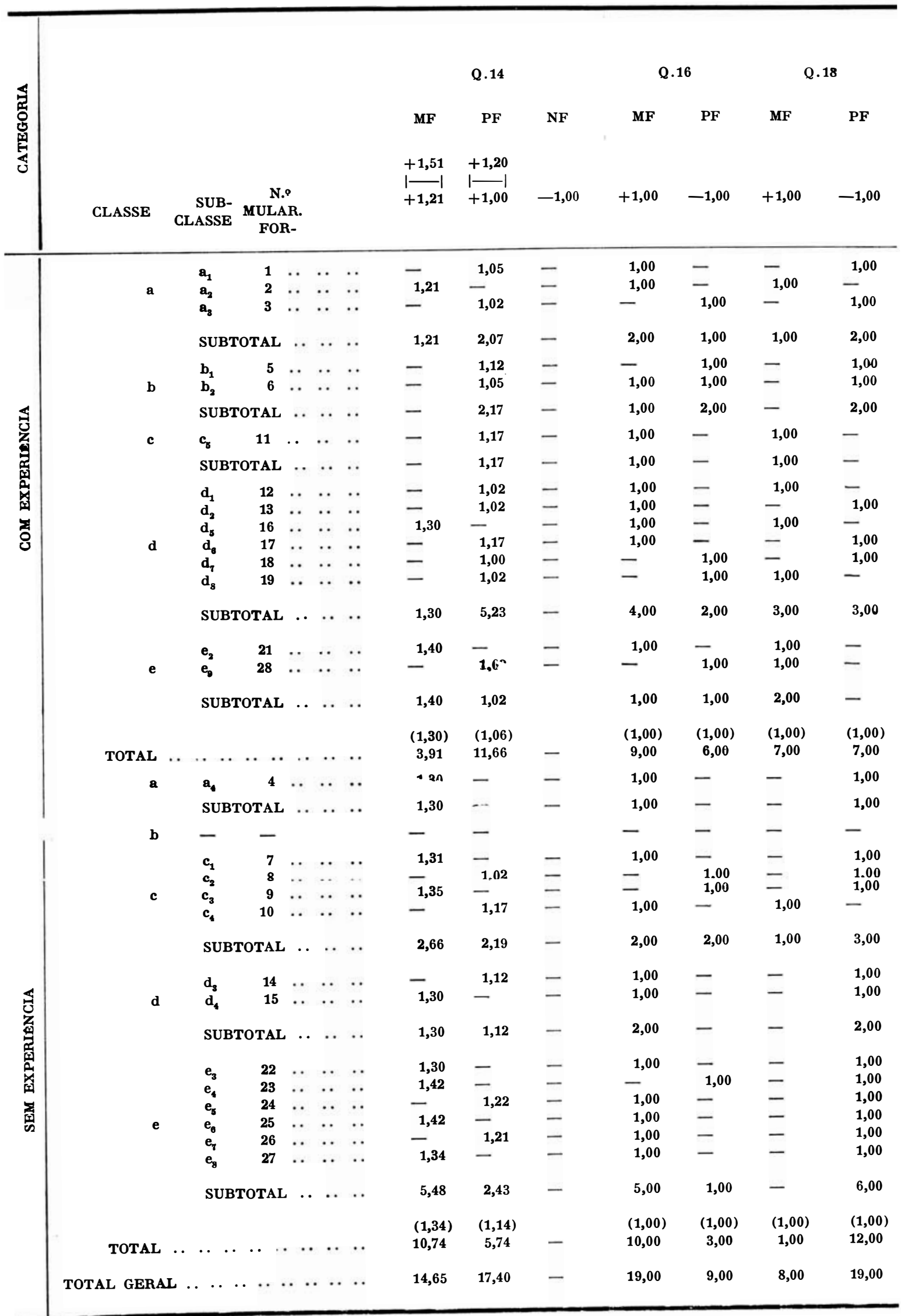

FONTE: RODRIGUES, M. L. - Pesquisa da conduta manifesta de 27 enfermeiras, sobre a utilização do Técnico LEGENDA : a, b, c, d, e = classes das entrevistadas.

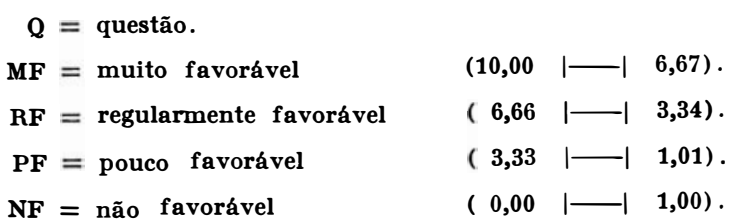


T A B E L A V I

DiSTRITO DE SÃO PAULO, ENTREVISTADAS RELATIVAMENTE A UTILIZAÇão DO TÉCNICO - MUNICfPIO DE SÃO PAULO, 1972

\begin{tabular}{|c|c|c|c|c|c|c|c|c|c|}
\hline \multirow[b]{2}{*}{ MF } & \multicolumn{2}{|l|}{ Q.19 } & \multicolumn{2}{|c|}{ Q.21 } & \multicolumn{3}{|c|}{ Q.22 } & \multicolumn{2}{|c|}{ Q.23 } \\
\hline & $\mathbf{R F}$ & PF & MF & PF & MF & $\mathbf{R F}$ & PF & MF & PF \\
\hline 1100 & $\frac{-0,01}{\mid-0,50}$ & $\frac{-0,51}{\mid-1,00}$ & $+1,00$ & -100 & $\begin{array}{l}+0,114 \\
\mid-0,1\end{array}$ & $\begin{array}{l}+0,006 \\
|-|\end{array}$ & & & \\
\hline- & - & 0,63 & 1,00 & - & - & 0,036 & - & 1,00 & - \\
\hline 1,00 & - & - & - & 1,00 & - & - & 1,00 & 1,00 & - \\
\hline- & - & 0,82 & - & 1,00 & - & - & 1,00 & 1,00 & - \\
\hline 1,00 & - & 1,45 & 1,00 & 2,00 & - & 0,036 & 2,00 & 3,00 & - \\
\hline- & - & 1,00 & 1,00 & - & - & 0,036 & - & - & 1,00 \\
\hline- & - & 0,92 & 1,00 & - & - & 0,099 & - & 1,00 & - \\
\hline - & - & 1,92 & 2,00 & - & - & 1,35 & - & 1,00 & 1,00 \\
\hline 1,00 & - & - & - & 1,00 & 0,135 & - & - & 1,00 & - \\
\hline 1,00 & - & - & - & 1,00 & 0,135 & - & - & 1,00 & - \\
\hline 1,00 & - & - & - & 1,00 & - & - & 1,00 & 1,00 & - \\
\hline- & - & 0,61 & - & 1,00 & - & - & 1,00 & 1,00 & - \\
\hline 1,00 & - & - & 1,00 & - & - & 0,099 & - & 1,00 & - \\
\hline- & 0,44 & - & 1,00 & - & - & 0,024 & - & 1,00 & - \\
\hline- & - & 0,54 & 1,00 & - & - & 0,018 & - & 1,00 & - \\
\hline 1,00 & - & - & 1,00 & - & - & 0,036 & - & 1,00 & - \\
\hline 3,00 & 0,44 & 1,15 & 4,00 & 2,00 & - & 0,177 & 2,00 & 6,00 & - \\
\hline 1,00 & - & - & 1,00 & - & 0,200 & - & - & 1,00 & - \\
\hline 1,00 & - & - & - & 1,00 & - & - & 1,00 & 1,00 & - \\
\hline 2,00 & - & - & 1.00 & 1,00 & 0,200 & - & 1,00 & 2,00 & - \\
\hline$(1,00)$ & & $(0,75)$ & $(1,00)$ & $(1,00)$ & $(0,167)$ & $(0,23)$ & $(1,00)$ & $(1,00)$ & \\
\hline 7,00 & 0,44 & 4,52 & 8,00 & 7,00 & 0,335 & 1,563 & 5,00 & 13,00 & 1,00 \\
\hline- & 0,22 & - & - & 1,00 & - & - & 1,00 & 1,00 & - \\
\hline- & 0,22 & - & - & 1,00 & - & - & 1,00 & 1,00 & - \\
\hline- & - & - & - & - & - & - & - & - & - \\
\hline- & - & 0,60 & 1,00 & - & - & 0,033 & - & 1,00 & - \\
\hline 二 & $\begin{array}{l}0.40 \\
0,50\end{array}$ & 二 & 二 & 1,00 & - & - & 1,00 & 1,00 & \\
\hline 1,00 & - & - & 1,00 & $\begin{array}{l}1,00 \\
-\end{array}$ & - & $\overline{0,006}$ & $\begin{array}{l}1,00 \\
-\end{array}$ & $\begin{array}{l}1,00 \\
1,00\end{array}$ & - \\
\hline 1,00 & 0,90 & 0,60 & 2,00 & 2,00 & - & 0,039 & 2,00 & 4,00 & - \\
\hline - & - & 1,00 & 1,00 & - & - & 0,054 & - & 1,00 & - \\
\hline - & - & 0,81 & 1,00 & - & - & 0,018 & - & 1,00 & - \\
\hline - & - & 1,81 & 2,00 & - & - & 0,072 & - & 2,00 & - \\
\hline- & - & $0,9 u$ & $\begin{array}{l}1,00 \\
1,00\end{array}$ & - & 0,117 & - & - & 1,00 & - \\
\hline - & $\overline{0,48}$ & $\begin{array}{l}0,59 \\
-\end{array}$ & $\begin{array}{l}1,00 \\
1,00\end{array}$ & - & 0,198 & - & - & 1,00 & - \\
\hline - & $\begin{array}{r}0,48 \\
0,11\end{array}$ & - & 1,00 & - & - & 0,036 & - & 1,00 & - \\
\hline - & - & 0,92 & 1,00 & - & - & 0,042 & - & 1,00 & - \\
\hline - & - & 1,00 & 1,00 & - & - & 0,018 & - & 1,00 & - \\
\hline & $0-50$ & & & - & 0,222 & - & - & 1,00 & - \\
\hline - & 0,59 & 3,41 & 6,00 & - & 0,537 & 0,096 & - & 6,00 & - \\
\hline$(1,00)$ & $(0,34)$ & $(0,83)$ & $(1,00)$ & $(1,00)$ & $(0,179)$ & $(0,029)$ & $(1,00)$ & $(1,00)$ & \\
\hline 1,00 & 1,71 & 5,82 & 10,00 & 3,00 & 0,537 & 0,207 & 3,00 & 13,00 & - \\
\hline 8,00 & 2,15 & 10,34 & 18,00 & 10,00 & 0,872 & 1,770 & 8,00 & 26,00 & 1,00 \\
\hline
\end{tabular}

de Enferinagem no Campo da Saúde Pública - São Paulo, 1972. 


\begin{tabular}{|c|c|c|c|c|c|c|c|c|c|c|}
\hline \multicolumn{2}{|c|}{ Q.24 } & \multicolumn{2}{|c|}{ Q.25 } & \multicolumn{3}{|c|}{ Q.26 } & \multicolumn{4}{|c|}{ TOT A L } \\
\hline MF & PF & MF & PF & MF & $\mathbf{R F}$ & PF & MF & RF & PF & NF \\
\hline & & & & $+1,56$ & $+1,36$ & $+1,00$ & $+6,71$ & $+3,40$ & $+1,00$ & 0,99 \\
\hline$+1,00$ & $-1,00$ & $+1,00$ & $-1,00$ & $+1,37$ & $+1,05$ & $-1,00$ & $+10,00$ & $+6,70$ & 3,30 & $\begin{array}{r}0,00 \mathrm{e} \\
-1,00\end{array}$ \\
\hline 1,00 & - & 1,00 & - & - & 1,23 & - & - & 5,69 & - & - \\
\hline 1,00 & - & 1,00 & - & - & 1,05 & - & - & 6,26 & - & - \\
\hline 1,00 & - & 1,00 & - & - & - & $+1,00$ & - & - & 0,20 & - \\
\hline 3,00 & - & 3,00 & - & - & 2,28 & $+1,00$ & - & $\begin{array}{l}(4,05) \\
11,95\end{array}$ & 0,20 & - \\
\hline- & 1,00 & - & 1,00 & - & - & $-1,00$ & - & - & - & $-4,84$ \\
\hline & - & 1,00 & - & - & - & $+1,00$ & - & 5,23 & - & - \\
\hline 1,00 & 1,00 & 1,00 & 1,00 & - & - & 0,00 & - & 5,23 & - & $-4,84$ \\
\hline 1,00 & - & 1,00 & - & - & 1,14 & - & 7,45 & - & - & - \\
\hline 1,00 & - & 1,00 & - & - & 1,14 & - & 7,45 & - & - & - \\
\hline 1,00 & - & 1,00 & - & - & - & $+1,00$ & - & 6,02 & - & - \\
\hline 1,00 & - & 1,00 & - & - & - & $+1,00$ & - & - & 2,41 & - \\
\hline 1,00 & - & 1,00 & - & 1,46 & - & - & 9,86 & - & - & - \\
\hline- & 1,00 & 1,00 & - & - & - & $+1,00$ & - & 3,75 & - & - \\
\hline 1,00 & - & 1,00 & - & - & - & $+1,00$ & - & 3,48 & - & - \\
\hline 1,00 & - & 1,00 & - & - & - & $+1,00$ & 7,56 & - & - & - \\
\hline 5,00 & 1,00 & 6,00 & - & 1,46 & - & $+5,00$ & $\begin{array}{l}(8,71) \\
17,42\end{array}$ & $\begin{array}{l}(4,41) \\
13,25\end{array}$ & 2,41 & - \\
\hline- & 1,00 & - & 1,00 & 1,40 & - & - & - & 6,00 & - & - \\
\hline 1,00 & - & 1,00 & - & - & - & $+1,00$ & - & 4,00 & - & - \\
\hline 1,00 & 1,00 & 1,00 & 1,00 & 1,40 & - & $+1,00$ & - & $\begin{array}{l}(5,00) \\
10,00\end{array}$ & - & - \\
\hline$(1,00)$ & $(1,00)$ & $(1,00)$ & $(1,00)$ & $(1,43)$ & $(1,71)$ & $(0,70)$ & $(8,29)$ & $(5,03)$ & & \\
\hline 11,00 & 3,00 & 12,00 & 2,00 & 2,86 & 3,42 & 7,00 & 24,87 & 40,23 & 2,61 & $-4,84$ \\
\hline 1,00 & - & 1,00 & - & - & 1,10 & - & - & - & 3,18 & - \\
\hline 1,00 & - & 1,00 & - & - & 1,10 & - & - & - & $\mathbf{3 , 1 8}$ & - \\
\hline- & - & - & - & - & - & - & - & - & - & - \\
\hline 1,00 & - & 1,00 & - & - & - & $+1,00$ & - & 5,74 & - & - \\
\hline 1,00 & & 1,00 & & & & $+1,00$ & - & - & 0,62 & - \\
\hline & - & 1,00 & - & 1,37 & - & - & - & - & 1,22 & - \\
\hline & - & 1,00 & - & - & 1,14 & - & 9,316 & - & - & - \\
\hline 4,00 & - & 4,00 & - & 1,37 & 1,14 & $+2,00$ & 9,316 & $\begin{array}{c}(4,25) \\
5,74\end{array}$ & 1,84 & - \\
\hline 1,00 & - & 1,00 & - & - & - & $+1,00$ & - & 5,174 & - & - \\
\hline 1,00 & - & 1,00 & - & - & - & $+1,00$ & - & 5,508 & - & - \\
\hline 2,00 & - & 2,00 & - & - & - & $+2,00$ & - & $\begin{array}{l}(5,34) \\
10,68\end{array}$ & - & - \\
\hline 1,00 & - & 1,00 & - & - & 1,22 & - & - & 5,73 & - & - \\
\hline 1,00 & - & 1,00 & - & - & 1,05 & - & - & 4,078 & - & - \\
\hline- & 1,00 & - & 1,00 & - & - & $+1,00$ & - & - & 1,776 & - \\
\hline 1,00 & - & 1,00 & - & 1,41 & - & - & 6,76 & - & - & - \\
\hline- & 1,00 & - & 1,00 & - & - & $+1,00$ & - & - & 1,308 & - \\
\hline- & 1,00 & - & 1,00 & - & - & $+1,00$ & - & - & 1,562 & - \\
\hline 3,00 & 3,00 & 3,00 & 3,00 & 1,41 & 2,27 & $+3,00$ & 6,76 & $\begin{array}{r}(4,90) \\
9,808\end{array}$ & $\begin{array}{c}(1,548) \\
4,646\end{array}$ & - \\
\hline$(1,00)$ & $(1,00)$ & $(1,00)$ & $(1,00)$ & $(1,39)$ & $(1,17)$ & $(1,00)$ & $(8,038)$ & $(5,245)$ & $(1,611)$ & \\
\hline 10,00 & 3,00 & 10,00 & 3,00 & 2,78 & 4,51 & 7,00 & 16,076 & 26,228 & 9,666 & - \\
\hline 21,00 & 6,00 & 22,00 & 5,00 & 5,64 & 7,93 & 14,00 & $\begin{array}{l}(8,189) \\
40,946\end{array}$ & $\begin{array}{l}(5,112) \\
66,458\end{array}$ & $\begin{array}{l}(1,534) \\
12,276\end{array}$ & $-4,84$ \\
\hline
\end{tabular}




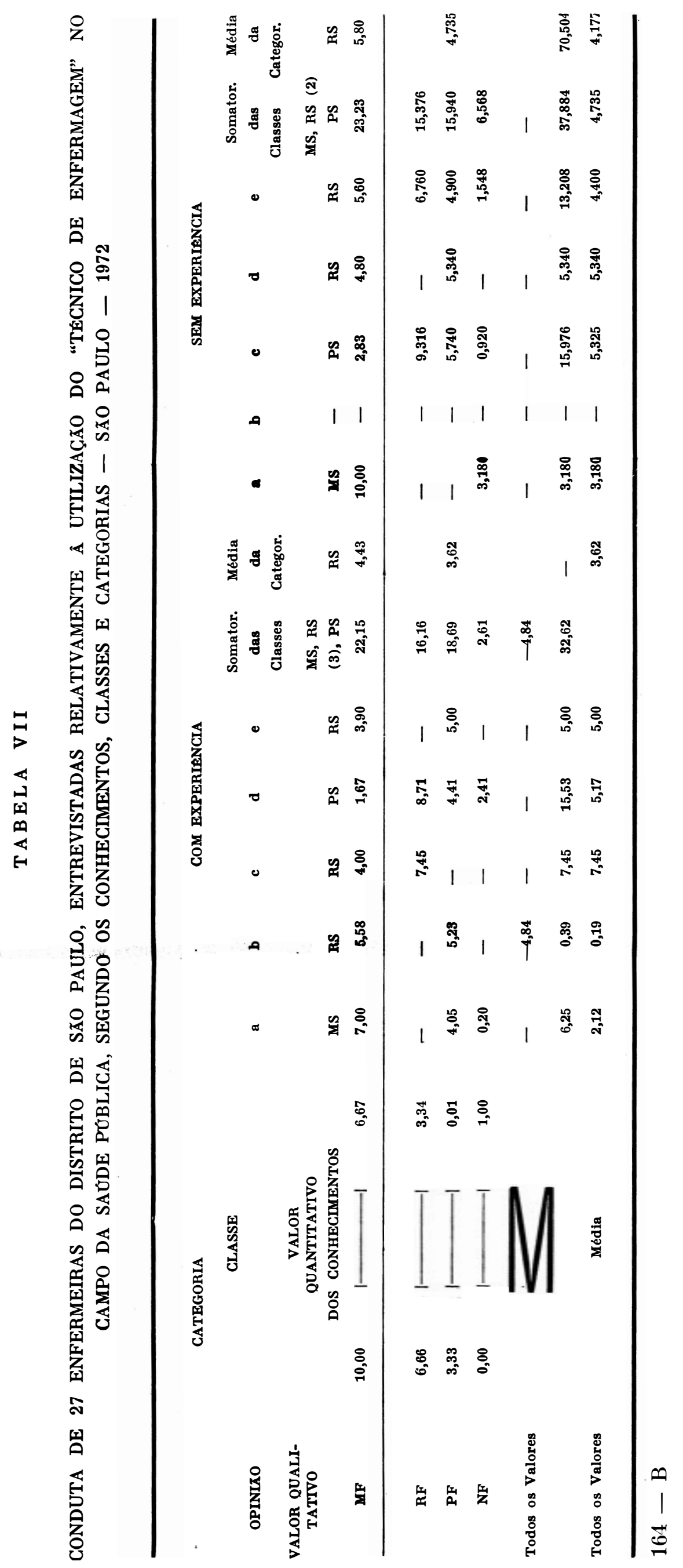


ANEXO 1

F O RMULARIO

1 - FUNÇÃO:

2 - A SENHORA SABE POR QUE FOI CRIADA A CATEgORIA DO "TECNICO DE ENFERMAGEM"?

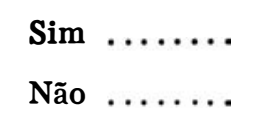

$3-($ CASO SIM $):$ POR QUE ?

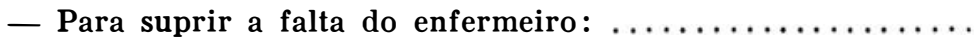

- Para suprir a falta do auxiliar de enfermagem: ........

- Para suprir a falta de pessoal de enfermagem:

- Por outra razão:

4 - A SENHORA SABE DIZER SE O ENSINO DO TÉCNICO DE ENFERMAGEM E REGULAMENTADO POR LEI?

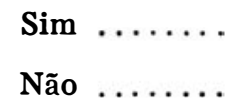

5 - A SENHORA SABE DIZER DE QUE CONSTA O ELENCO DAS DISCIPLINAS DO CURRACULO DO TÉCNICO DE ENFERMAGEM?

$\operatorname{Sim} \ldots \ldots \ldots$

Não $\ldots \ldots \ldots$ 
6 - (CASO SIM) : QUAIS SÃO?

Matérias Básicas

7 - A SENHORA SABE SE JA FORAM ESPECIFICADAS AS ATRIBUIÇÕES DO TECCNICO DE ENFERMAGEM?

- Já foram especificadas:

- Ainda não foram especificadas:

- Não sabe:

8 - (CASO JA TENHAM SIDO ESPECIFICADAS) : SABE DIZER SE A ESPECIFICAÇÃO FOI:

- Na área da enfermagem hospitalar:

- Na área da enfermagem de saúde pública:

- Sem especificação da área de enfermagem:

- Não sabe:

9 - O EXERCfCIO DO TÉCNICO DE ENFERMAGEM JA FOI REGULAMENTADO POR LEI?

Sim

Não

Não sabe

10 - A SENHORA JA TEVE ALGUMA EXPERIÊNCIA PROFISSIONAL COMO TECNICO DE ENFERMAGEM?

Sim

Não

11 -- (CASO SIM): ESTA EXPERIENCIA FOI EM QUE AREA?

- No ensino:

- Na legislação pertinente:

- No trabalho hospitalar:

- No trabalho de saúde pública: 
12. - EM SEU SETOR DE TRABALHO EXISTE TÉCNICO DE ENFERMAGEM?

Sim

Não

13 - (CASO SIM): QUE ATIVIDADES LHE FORAM CONFERIDAS?

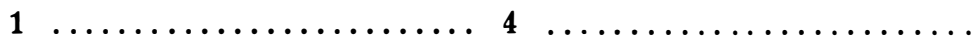

$2 \ldots \ldots \ldots \ldots \ldots \ldots \ldots \ldots \ldots, 5, \ldots \ldots \ldots \ldots \ldots \ldots \ldots \ldots$

$3 \ldots \ldots \ldots \ldots \ldots \ldots \ldots, 6$

14 - NA SUA OPINIÃO, A SITUAÇÃO DA ENFERMAGEM NO BRASIL, ESPECIFICAMENTE EM SÃO PAULO, AINDA JUSTIFICARIA A UTILIZAÇÃO DO PESSOAL DE ENFERMAGEM DE NfVEL MÉDIO EM SAÚDE PÚBLICA?

- Sim ...... Por quê?

- Não ...... Por quê?

OBS.: (SE A PESSOA TIVER RESPONDIDO “NÃO”, ENCERRAR A ENTREVISTA.)

15 - DENTRE AS ATIVIDADES DE ENFERMAGEM DE SAÚDE PÚBLICA QUAIS AS QUE A SENHORA ATRIBUIRIA AO TÉCNICO DE ENFERMAGEM?

(Ver folha de instruções e anotar as respostas para números correspondentes)

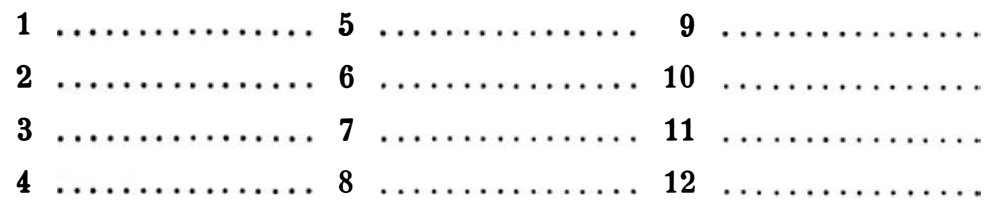


16 - QUE CATEGORIA DE PESSOAL A SENHORA ACHA PRIORITÁRIA PARA O TRABALHO DE ENFERMAGEM EM SAÚDE PÚBLICA, EM NIVEL LOCAL?

- Técnico de enfermagem: $\ldots \ldots \ldots \ldots \ldots \ldots \ldots \ldots \ldots \ldots$

- Auxiliar de enfermagem:

- Técnico e auxiliar com importância equivalente: .......

- Não sabe:

17 - NA SUA OPINIÃO, EM QUE NIVEL DA ORGANIZAÇÃO DOS SERVIÇOS DE SAÚDE PÚBLICA SERIA JUSTIFICADA A PRESENÇA DO TÉCNICO DE ENFERMAGEM?

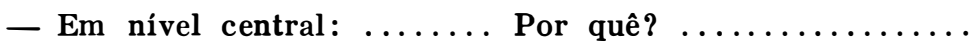

- Em nível regional: Por quê?

- Em nível local:

- Não sabe:

18 - A SITUAÇÃO ATUAL DA ENFERMAGEM NO BRASIL JUSTIFICA A UTILIZAÇÃO DO TÉCNICO DE ENFERMAGEM NA ÁREA DA SAÚDE PÚBLICA. NA SUA OPINIÃO, EXISTE ALGUM FATOR QUE DIFICULTARIA ESTA UTILIZAÇÃO?

$$
\begin{aligned}
& \text { Sim } \ldots \ldots \cdots \\
& \text { Não } . . . \cdots
\end{aligned}
$$

19 - (CASO SIM) : A QUE FATORES A SENHORA CONDICIONARIA A UTILIZAÇÃO DO TÉCNICO DE ENFERMAGEM EM SAƯDE PÚBLICA?

a) A melhor aceitação do Técnico de Enfermagem no meio

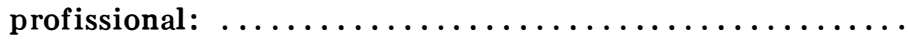

b) A regulamentação do exercício profissional do Técnico

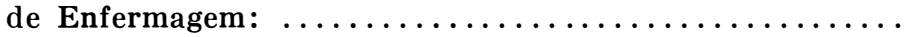

c) A regularização da utilização do enfermeiro na Secretaria de Estado da Saúde do Estado de São Paulo: ......... 
d) A estruturação da carreira do Técnico de Enfermagem em Saúde Pública na Secretaria de Estado da Saúde do Estado de São Paulo:

e) À definição das funções do Técnico de Enfermagem em Saúde Pública:

f) Ao preparo adequado para o trabalho:

g) A maiores esclarecimentos sobre a categoria do Técnico de Enfermagem no meio profissional:

h) Outros:

i) Não sabe:

20 - QUE ASPECTOS A SENHORA APONTARIA COMO SENDO DA RESPONSABILIDADE DO ENFERMEIRO EM RELAÇÃO AO PESSOAL AUXILIAR?

- Preparo adequado do próprio enfermeiro: ..........

-. Ensino:

- Planejamento do trabalho:

- Provisão de condições adequadas ao trabalho: ........

- Direção científica eficiente: ................

- Atuação positiva na estruturação da carreira do T.E.: . .

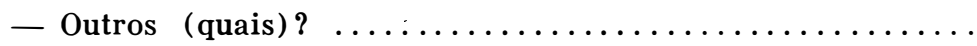

21 - A SENHORA TEM AlgUma SUGESTÃo A FAZER RELATIVA A UTILIZAÇÃO DO TÉCNICO DE ENFERMAGEM?

$\operatorname{Sim} \ldots \ldots \ldots$

Não

22 - (CASO SIM) : QUAL? 
23 - NA SUA OPINIÃO, O PROBLEMA DA INCLUSÃO DO TÉCNICO DE ENFERMAGEM NA EQUIPE DE ENFERMAGEM DE SAÚDE PÚBLICA DEVE SER DISCUTIDO PARA QUE POSSA SER PREVISTA A SUA INCLUSÃO NA ESTRUTURA DO SERVIÇO DE SAÚDE PÚBLICA DO ESTADO?

$$
\begin{aligned}
& \text { Sim } \ldots \ldots \ldots \\
& \text { Não } \ldots \ldots \cdots \\
& \text { Não } \\
& \text { sabe } \ldots \ldots
\end{aligned}
$$

OBS.: (CASO SIM): ENCERRAR A ENTREVISTA

24 - NA SUA OPINIÃO, O PROBLEMA DA INCLUSÃO DO TÉCNICO DE ENFERMAGEM NA EQUIPE DE ENFERMAGEM DE SAÚDE PÚBLICA DEVE AGUARDAR QUE SEJA DEFINITIVAMENTE RESOLVIDO O PROBLEMA DA UTILIZAÇÃO DO ENFERMEIRO NOS SERVIÇOS DE SAÚDE PÚBLICA DO ESTADO?

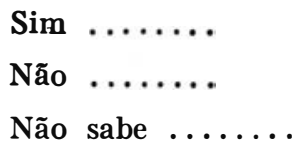

OBS.: (CASO SIM): ENCERRAR A ENTREVISTA

25 - NA SUA OPINIÃO, O PROBLEMA DA INCLUSÃO DO TÉCNICO DE ENFERMAGEM NA EQUIPE DE ENFERMAGEM DE SAÚDE PÚBLICA DEVE ESPERAR QUE O PROBLEMA SE APRESENTE ESPONTANEAMENTE PARA SER DEBATIDO?

$$
\begin{aligned}
& \text { Sim } \ldots \ldots \ldots \\
& \text { Não } \ldots \ldots \ldots \\
& \text { Não sabe } \ldots \ldots \ldots
\end{aligned}
$$

OBS.: (CASO SIM) : ENCERRAR A ENTREVISTA

26 - NA SUA OPINIÃO, O PROBLEMA DA INCLUSÃO DO TÉCNICO DE ENFERMAGEM NA EQUIPE DE ENFERMAGEM DE SAÚDE PÚBLICA DEVE SER ESTUDADO?

$-\operatorname{Sim} \ldots \ldots$ Sob que aspecto $\ldots \ldots \ldots \ldots \ldots \ldots \ldots$

- Não ........

— Não sabe 